\title{
Verbalization and Visualisation Effect on Football Technical Learning Using Loughborough Soccer Passing Test (LSPT)
}

\section{Hammamai Med Ali', Guninoubi Chameseddine1, Hajer Sehli1, Saber Abdelawi², Guerchi Maher3, Zghibi Makrem1}

\author{
${ }^{1}$ Institu Supérieur du Sport et de l'Education Physique Kef (ISSEP Kef), Kef, Tunisia \\ ${ }^{2}$ Institu Supérieur du Sport et de l'Education Physique Ksar Said (ISSEP Ksar Said), Tunis, Tunisia \\ ${ }^{3}$ Institu Supérieur du Sport et de l'Education Physique Gafsa (ISSEP Gafsa), Gafsa, Tunisia \\ Email: makwiss@yahoo.fr
}

How to cite this paper: Ali, H. M., Chameseddine, G., Sehli, H., Abdelawi, S., Maher, G., \& Makrem, Z. (2016) Verbalization and Visualisation Effect on Football Technical Learning Using Loughborough Soccer Passing Test (LSPT). Creative Education, 7, 2524-2531.

http://dx.doi.org/10.4236/ce.2016.716239

Received: July 2, 2016

Accepted: October 25, 2016

Published: October 28, 2016

Copyright $\odot 2016$ by authors and Scientific Research Publishing Inc. This work is licensed under the Creative Commons Attribution International License (CC BY 4.0).

http://creativecommons.org/licenses/by/4.0/

(c) (i) Open Access

\begin{abstract}
The purpose of this study is to verify verbalization and visualisation effect on learning basic technical elements with three male groups having the same educational level (basic 9th) and the same chronological age (15.5+/- 0.5). Anthropometric measurements and soccer skill performances were assessed. In the six technical learning sessions and through Loughborough Soccer Passing Test (LSPT) (Ali et al 2008), the group number one (G1) worked regular meetings without verbalization, the second group (G2) worked with students-students oral verbalization and the third group (G3) has worked with teacher-student oral verbalization and visualization through the demonstration of the LSPT test by an expert. Data showed no significant differences in height and weight between groups. While results showed, significant differences between three groups were in favour of G3 compared to G2 and G1 and that were in favour of G2 compared to G1, which leads us to conclude that there is an effect of verbalization and visualization on learning football basic technical elements with different degrees according to the ways of verbalization. It is pertinent to conclude that football technical learning for boys in schools is influenced by oral verbalization and visualization effect.
\end{abstract}

\section{Keywords}

Verbalization, Technical Learning, Visualization, Football, LSPT

\section{Introduction}

Verbalization of students is often seen as a tool to develop their reflective practice, their 
learning strategies, their metacognition (Poussin, Dénervaud, \& Lenzen, 2013). Students are expected to exchange ideas in the teaching learning process to advance and have positive results (Lafon \& Martin, 2014). Furthermore, when the effects of verbalization are minimal, the researchers feel significant progress in student language skills (Zghibi, Zerai, \& Rezig, 2009), thereby demonstrating an indirect benefit but significant of this socioconstructivist teaching modality of physical education. The teachinglearning process is determined by the teacher and the learner in an educational context (Dyson, 1995). And some studies identify the language interactions in didactic situations about a confrontation in collective games (Chang et al., 2006; Gréhaigne, 2009). Instructional visualizations have become an ubiquitous means to enhance players' learning complex patterns and playing schemes which are often difficult to verbalize. Instructional visualizations are external representations or visual-spatial displays printed on paper or shown on a computer screen that can be perceived by a person, whereas internal visualizations refer to representations in the mind of a person (Cohen \& Hegarty, 2007a, 2007b; Hegarty \& Waller, 2005).

Mayer (2001) showed that in order to explain the plans and phases of play to their players, football coaches usually use two main media types: Verbal and Visual. According to the Learning Multimedia theory (TAM) Mayer (2001), a double information coding (visual and auditory) increases the storage capacity of working memory, reduces unnecessary cognitive load and therefore promotes the learning process, especially for novice learners.

Technical abilities are important components of soccer performance. In particular, short-passing ability is considered a relevant skill for soccer players (Sajadi \& Rahnama, 2006). Indeed, short-passing accuracy as measured using the Lough-borough Soccer Passing Test (LSPT) is able to discriminate players of different competitive levels and to assess the multifaceted aspects of soccer skill including passing, dribbling, control and decision-making.

The aim of this study is to identify the best transmission means of visual and/or verbal information likely to accelerate the memorization of technical abilities that stands as important components of soccer performance through the use of Lougborough Soccer Passing Test (LSPT).

\section{Method}

\subsection{Participants}

Ninety school boys participated in our study. They were divided into three groups (G1; G2 and G3) of 30 students each. They have same educational level (basic 9th) and same chronological age $(15.5+/-0.5)$. They participated only in the compulsory physical education curriculum at school for at least 2 years at a rate of two weekly sessions of 50 min each. Generally the physical education session consists of 10 min warming up with low-intensity games and stretching exercises and 30 - 35 min of technical exercises (kicking actions, dribbling, jumping, and running with fast accelerations and decelerations) and 10 min of active recovery. 
The participants of our study were randomly chosen and were representative of the general population of students. At the beginning of the study, according to their pubescent status, the young school boys belonged to Tanner stage (2 - 3).

Local ethics committee approval was obtained prior to the start of testing and written informed consent was received from all participants and parents after verbal and written explanation of the experimental design and potential risks of the study.

\subsection{Anthropometric Characteristics}

Each participant came to the school medical center for medical examination and anthropometric measurements performed by a paediatrician before passing the test. Body height and body mass were measured with standard techniques to the nearest $0.1 \mathrm{~cm}$ and $0.1 \mathrm{~kg}$, respectively for each subject. All measurements were taken the morning at $7 \mathrm{~h} 30$ by the same investigator.

\subsection{Puberty Stage Assessment}

The puberty stage was the indicator of biological maturity status. It was determined and recorded by a paediatrician experienced in the assessment of secondary sex characteristics according to Tanner method (1975). Boys at pubertal development stages 1-5 were evaluated. According to their pubescent status, the young students belonged to Tanner stage $(2-3)$.

\subsection{LSPT Test Presentation}

Due to previous tests weakness, the LSPT was developed to assess the multifaceted aspect of soccer skill including passing. The first version of the LSPT was used, which has been shown to be both reliable and valid and it was validated by Ajmol et al. for use with female players. The detailed protocol and a schematic representation of the test have been presented elsewhere (Ali et al., 2007). All subjects were familiarised with the LSPT during 1-week (4 times/week) before testing to obtain an objective measure of short-passing ability. Figure 1 illustrates the layout of the LSPT.

Four wooden rebound boards were placed as shown on each of the four lines marking the $12 \times 9.5 \mathrm{~m}$ grid (to the inside of the boards). Prior to placement, four coloured target areas (red, blue, white and green; $0.6 \times 0.3 \mathrm{~m}$ ) were painted on the middle of each board. In addition, a $0.1 \times 0.15 \mathrm{~m}$ piece of aluminium was attached vertically in the middle of the target areas. The strip was screwed onto the board only on the top thus leaving the bottom hanging free; therefore, when the ball hit the centre of the strip, the player had audible reinforcement of a successful pass. Yellow tape was also used to mark the inner $(1 \times 2.5 \mathrm{~m})$ and outer $(2.5 \times 4 \mathrm{~m})$ rectangles and the passing zone was the area between these lines. Coloured cones were used to distinguish the different zones, with a further cone situated in the middle of the inner rectangular grid.

\section{1) Instructions and penalties for the passing test (LSPT)}

The participants began with the ball by the central cone, and the first examiner started timing the test, using a hand-held stopwatch (Accusplit, model $725 \mathrm{xp}$ ), from 


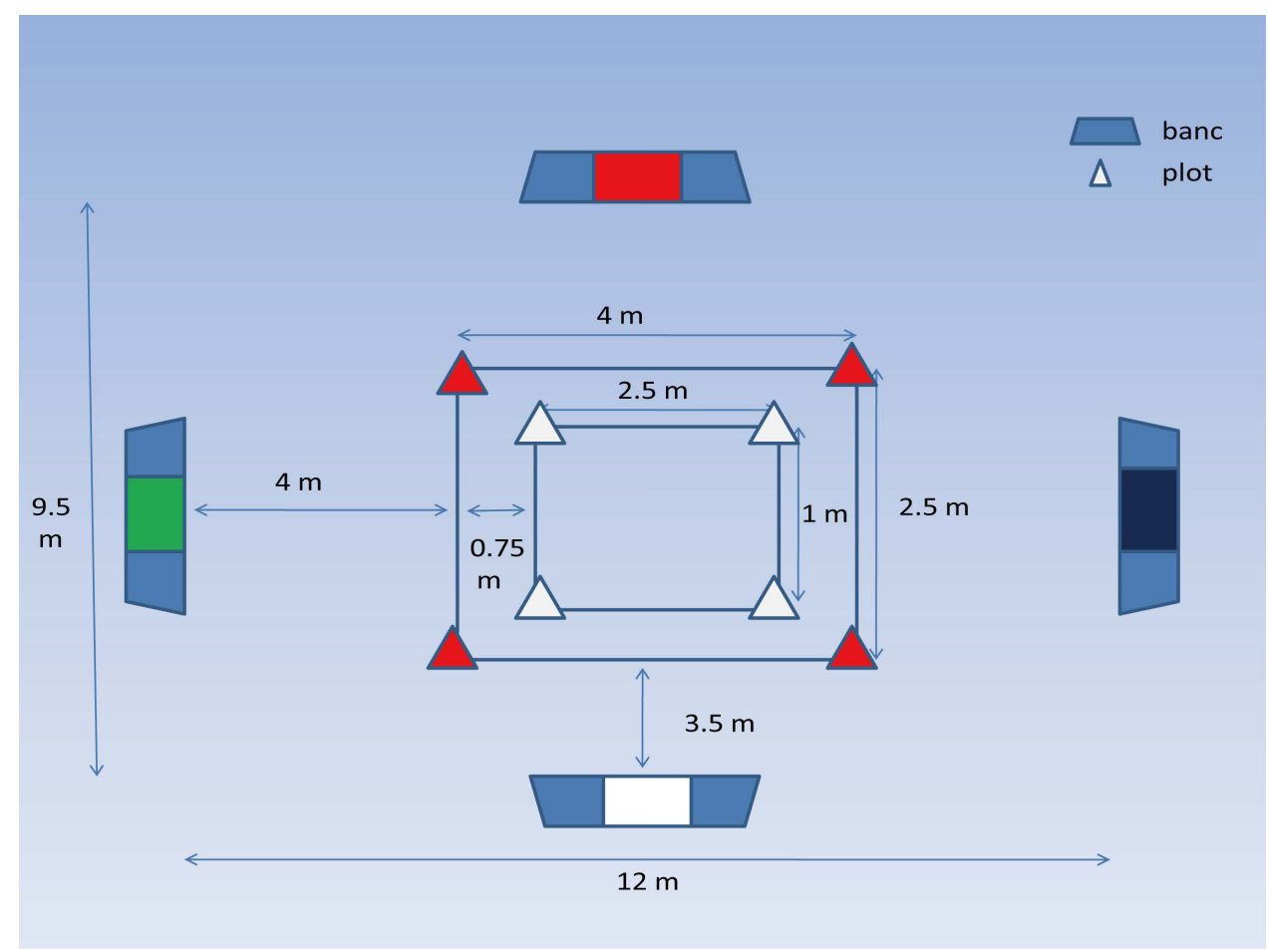

Figure 1. Schematic representation of the Loughborough Soccer Passing Test (LSPT).

the moment the ball was touched forward out of the inner rectangle. The second examiner was involved in calling out the order of passes; the specific colour was called out just before the participant completed the current pass. The same examiner was used in each role so as to eliminate inter-experimenter variability. The order of passes was determined by one of four trial orders that were randomly generated by the investigators so that each trial consisted of eight long (green and blue) and eight short (white and red) passes. The participants were informed that passes could only be executed from within the passing area, between the set of marked lines (see Figure 1). They were also told that upon retrieval from the previous pass, the ball had to cross two of the inner marked lines before the next pass could be attempted. Furthermore, the players were informed that for best performance on the LSPT they would have to perform the test as quickly as possible while making the fewest mistakes. The second examiner stopped the clock when the last pass made contact with the target area. The players were not given any knowledge of results (KR) or knowledge of performance (KP) feedback at any time during the data collection period.

The role of the second examiner was also to record penalty time points accrued during the trials. Thus, the examiner stood in such a position that all four target areas could be viewed.

Penalty time was awarded for the following errors:

$\star 5 \mathrm{~s}$ for missing the bench completely or passing to the wrong bench;

$\star 3 \mathrm{~s}$ for missing the target area $(0.6 \times 0.3 \mathrm{~m})$;

$\star 3 \mathrm{~s}$ for handing the ball; 
$* 2 s$ if the ball touched any cone;

${ }^{*} 1 \mathrm{~s}$ for every second taken over the allocated $43 \mathrm{~s}$ to complete the test;

${ }^{*} 1 \mathrm{~s}$ was deducted from the total time if the ball hit the $10-\mathrm{cm}$ strip in the middle of the target.

\section{2) Experiment steps}

To obtain an objective measurement of short-passing ability, the modified version of LSPT was used, in which the contribution of cognitive function (decision making) was added to the original passing test. This version of LSPT has been shown to be a reliable and valid the passing ability test. The LSPT test were made by the same investigators, scheduled at the same time of day, carried out in the same order and using the same apparatus at each student passage. Because it was demonstrated that LSPT TP was correlated with body mass and height, we have chosen our population almost with the same height and weight. The day of test, all students make 15 - 20 min of warming up with low-intensity games and stretching exercises then all subjects were familiarised with the LSPT before testing.

The group number one (G1) performed 3 trials in total and 10-minute recovery and worked without verbalization. G2 performed 3 trials in total and 10-minute recovery between each trial with student-student oral verbalization. During the oral verbalization, students discuss their mistakes, their technical execution, their penalties, and they exchange ideas especially from students who have achieved the best performance. G3 performed also 3 trials in total and 10-minute recovery between each trial with teacherstudent oral verbalization and visualization through the demonstration of LSPT test by an expert. During this passage, students and teachers exchanged ideas about the mistakes and students receive instructions and corrections by their teachers and he giving them some solutions to the encountered problems during their test and all students of G3 assist necessarily a gesture of demonstration by an expert to LSPT test. So all subjects of three groups (G1; G2 and G3) performed 3 trials in total and the best LSPT total performance times were selected for analysis.

\section{Statistical Analysis}

Results are expressed as means \pm standard deviations (SD). Significant differences were assumed when $p<0.05$. Data were analysed by using SPSS for Windows (version 16.0; SPSS Inc, Chicago). All variables used in the study were checked for normality of distribution before the analyses, Kolmogorov-Smirnov tests were used for each variable. A two way repeated analysis variance measurement (ANOVA) $(2 \times 2)$ was performed to determine if significant differences existed between groups.

\section{Results}

The participant anthropometric characteristics are presented in Table 1. No statistically significant differences were found between the three groups of the study in weight and in height.

A mean of the LSPT performance scores for all participants is presented in Table 2. 
Table 1. Anthropometric characteristics of groups G1; G2 and G3. Data presented as means \pm S.

\begin{tabular}{|c|c|c|c|c|c|c|}
\hline \multirow{3}{*}{$\begin{array}{l}\text { Variables } \\
\text { Height }(\mathrm{cm})\end{array}$} & \multicolumn{3}{|c|}{ Groups } & \multicolumn{3}{|c|}{ \#: difference between groups } \\
\hline & & & & \# & \# & \# \\
\hline & Gl & G2 & G3 & G2-G1 & G3-G1 & G3-G2 \\
\hline & $156.5 \pm 8.2$ & $156.9 \pm 7.1$ & $156.3 \pm 5.2$ & $0.4^{\mathrm{ns}}$ & $0.2^{\mathrm{ns}}$ & $0.6^{\mathrm{ns}}$ \\
\hline Weight $(\mathrm{kg})$ & $62.6 \pm 4.8$ & $62.9 \pm 7.3$ & $61.9 \pm 6.4$ & $0.3^{\text {ns }}$ & $0.7^{\mathrm{ns}}$ & $1.0^{\mathrm{ns}}$ \\
\hline
\end{tabular}

G1: group 1; G2: group 2; G3: group 3; \#: difference between groups; n.s: no significant.

Table 2. Performance scores of Loughborough Soccer Passing Test (LSPT) of different groups G1; G2 and G3 and effect of verbalization and visualisation. Data presented as means \pm S.

\begin{tabular}{|c|c|c|c|c|c|c|}
\hline \multirow[t]{2}{*}{ Variables } & \multicolumn{3}{|c|}{ Groups } & \multicolumn{3}{|c|}{ \#: Difference between groups } \\
\hline & $\begin{array}{c}\text { G1 } \\
\text { without } \\
\text { verbalization }\end{array}$ & $\begin{array}{c}\mathrm{G} 2 \\
\text { verbalization } \\
\text { student-student }\end{array}$ & $\begin{array}{c}\text { G3 } \\
\text { Verbalization } \\
\text { teacher-student } \\
\text { + visualisation }\end{array}$ & $\begin{array}{c}\# \\
\text { G1 - G2 }\end{array}$ & $\begin{array}{c}\# \\
\text { G2 - G3 }\end{array}$ & $\begin{array}{c}\# \\
\text { G1 - G3 }\end{array}$ \\
\hline LSPT T (s) & $56.2 \pm 3.7$ & $55.3 \pm 4.3$ & $49.5 \pm 4.7$ & $0.9^{\text {ns }}$ & $5.8^{* *}$ & $6.7^{* *}$ \\
\hline LSPT P (s) & $16.3 \pm 4.8$ & $13.2 \pm 3.7$ & $9.4 \pm 3.8$ & $3.1^{*}$ & $3.8^{*}$ & $6.8^{* *}$ \\
\hline LSPT TP (s) & $72.5 \pm 7.4$ & $62.8 \pm 4.3$ & $58.9 \pm 5.4$ & $9.7^{* *}$ & $3.9^{*}$ & $13.6^{* *}$ \\
\hline
\end{tabular}

Data presented as means \pm S; LSPT T: Loughborough Soccer Passing Test time (s); LSPT P: Loughborough Soccer Passing Test penalty (s); LSPT TP: Loughborough Soccer Passing Test total performance (s); \#: Difference between groups; G1: group1; G2: group2; G3: group3; *: significant at $p<0.05$; **: significant at $p<0.001$.

The performance score (LSPT TP) consists of two variables, the time taken to complete the LSPT (LSPT T) and any accrued penalty time (LSPT P) for poor control or inaccurate passing. Results showed significant differences between the three groups in favour for G3 (verbalization teacher-student and visualisation) compared to G2 (verbalization student-student) $(p<0.05)$ and G1 (Without verbalization) $(p<0.001)$ and in favour for $\mathrm{G} 2$ compared to $\mathrm{G} 1(p<0.001)$.

\section{Discussion}

Several experimental studies and literature reviews have examined the effects of verbalization on motor learning in contexts and with different aims of verbalization (Lafont \& Martin, 2014). In this contribution, we focus on the process of acquiring motor skills through physical education, and more specifically to the use of verbalization of the student in this process. The use of student verbalization is indeed often advocated in the didactic proposals, the official texts and in the training process of physical education teachers (Attali \& St.-Martin, 2010; Delignières 1991; Deriaz, Chick \& Gréhaigne, 1998). Results of this research showed the positive effects of these discussions of ideas on the development of motor skills (Lafont et al., 2007). In the same way, Delignières (1991) denounced a massive use of verbalization procedures in the teaching of physical education and he said that "It is striking how students currently are supposed to think and verbalize in physical education and sport session".

In the present study, our result showed that students of (G1) who have completed the 
LSPT without verbalization could not improve their total performance time. While a significant differences in improving total performance was observed between the three groups in favour of G3 (verbalization teacher-student and visualisation) compared to G2 (verbalization student-student) $(p<0.05)$ and G1 (Without verbalization) $(p<$ $0.001)$ and in favour of G2 compared to G1 $(p<0.001)$. And our results were in agreement with other researches like Lafont et al. who mentioned that it seems necessary that the teacher during his demonstration of a dance sequence, "active" verbal channel for participants to benefit from their own verbalization activity (Lafont \& Martin, 2014) and Cadopi et al. who said that student verbalizes to develop a reference and to reproduce the figure or the sequence requested, and also to evaluate those executed or those he has seen (Cadopi, 2005). In the same Elandoulsi (2006) showed the positive effects of verbal intercommunications between pupils on motor acquisition on learning of tendon support overthrown in gymnastics. Also in volleyball, Guerin and Saury observed and analyzed a positive verbalization of a student by another student, within a working group of 13 years. Make verbalize the student is sometimes the only means available to teachers for his successful teaching-learning. However, Lafont \& Martin, (2014) demonstrate that verbal repetition of the sequence observed by students aged 11 to 12 years was only effective if the teacher had previously used the demonstration and the teacher can ask participants to verbalize the sequence that has previously demonstrated. In some cases, especially when learning situations, the teacher equips students of observation sheets; intended for the collection of predefined information on the motor behaviour can fuel an oral analysis of this information (Cogérino, 2002). For future research we hope to do the same study for a female population and then make a comparative study on the results of both sex and compare with other studies at the international level to find themselves in relation to others.

\section{Conclusion}

In conclusion, we can conclude that there is verbalization and visualization effect on learning football basic technical elements with different degrees according to the ways of verbalization. It is pertinent to conclude that technical learning football for boys in school is influenced by oral verbalization and visualization effect.

\section{References}

Ali, A., Foskett, A., \& Gant, N. (2008). Validation of a Soccer Skill Test for Use with Females. International Journal Sports Medicine, 29, 917-921. http://dx.doi.org/10.1055/s-2008-1038622

Ali, A., Williams, C., Hulse, M. A. et al. (2007). Reliability and Validity of Two Tests Of Soccer Skill. Journal of Sports Sciences, 25, 1461-1470. http://dx.doi.org/10.1080/02640410601150470

Attali, M., \& Saint-Martin, J. (2010). The Evaluation EPS: between Disciplinary Legitimacy and Cultural Challenges (1959-2009). The Science of Education-For the New Era, 43, 55-81.

Cadopi, M. (2005). Motor Skills of the Dancer: Cognitive Approach. Psychology Bulletin, 475, 2937. http://dx.doi.org/10.3917/bupsy.475.0029

Chang, C. W., Wallian, N., Nachon, M., \& Gréhaigne, J.-F. (2006). Language Practices and Strategies for Action: Towards a Semiotic-Constructivist Approach of Basketball. Taiwan Stamps, 
72, 63-77.

Cogérino, G. (2002). The Difficulties of Evaluation in EP: The Case of Accompanying Knowledge. Staps, 59, 23-42. http://dx.doi.org/10.3917/sta.059.0023

Cohen, C. A., \& Hegarty, M. (2007a). Individual Differences in Use of an External Visualization While Performing an Internal Visualization Task. Applied Cognitive Psychology, 21, 701-711. http://dx.doi.org/10.1002/acp.1344

Delignières, D. (1991). Motor Learning and Verbalization. Exchanges and Controversies, 4, 2942.

Deriaz, D., Poussin, B., \& Gréhaigne, J.-F. (1998). Collective Sports Games at School: The Debate of Ideas. EPS Review, 273, 80-82.

Dyson, B. P. (1995). Students' Voices in Alternative Elementary Physical Education Programs. Journal of Teaching in Physical Education, 14, 394-407. http://dx.doi.org/10.1123/jtpe.14.4.394

Elandoulsi, S. (2006). Effects of Verbal Intercommunications between Pupils on Motor Learning: Example Learning the Handstand in Gymnastics. Staps, 74, 41-45. http://dx.doi.org/10.3917/sta.074.0041

Gréhaigne, J. F. (2009). Around Time. Spaces, Learning, Projects in team Sports. Besançon: University Press of Franche-Comté.

Hegarty, M., \& Waller, D. (2005). Individual Differences in Spatial Abilities. In P. Shah \& A. Miake (Eds.), The Cambridge Handbook of Visuospatial Thinkink (p. 121). Cambridge: Cambridge University Press. http://dx.doi.org/10.1017/cbo9780511610448.005

Lafont, L. \& Martin, L. (2014). Learning and Teaching in Physical Activity Artistic Dimension: Theoretical Considerations and Research Results. STAPS, 103, 39-52. http://dx.doi.org/10.3917/sta.103.0039

Lafont, L., Proeres, M., \& Vallet, C. (2007). Cooperative Group Learning in a Team Game: Role of Verbal Exchanges among Peers. Social Psychology of Education, 10, 93-113. http://dx.doi.org/10.1007/s11218-006-9006-7

Mayer, R. E. (2001). Psychology of Learning and Motivation. Multimedia Learning. Cambridge: Cambridge University Press. http://dx.doi.org/10.1017/cbo9781139164603

Patinet-Bienaimé, C., \& Cogérino, G. (2002). Subjective Experiences of Diversity in EPS: Explanation and Practical Unveiling of Identity Issues. STAPS, 96-97, 49-65. http://dx.doi.org/10.3917/sta.096.0049

Poussin, B., Dénervaud, H., \& Lenzen, B. (2013). The Contribution of Physical Education to the Development of Reflexive Approach Students: What Teaching Techniques Used by Teachers during a Volleyball Cycle? JRIEPS, 30, 53-69.

Sajadi, N., \& Rahnama, N. (2006) Analysis of Goals in 2006 FIFA World Cup. Journal of Sports Science and Medicine, 6, 3.

Zghibi, M., Zerai, Z., \& Rezig, M. (2009). Verbalization's Direct Effects on Action's Strategies and Decision Makings among Pupils at a Football Cycle. Journal of Research about the Intervention on Physical and Sportive Education, 16, 118-140. 
Submit or recommend next manuscript to SCIRP and we will provide best service for you:

Accepting pre-submission inquiries through Email, Facebook, LinkedIn, Twitter, etc. A wide selection of journals (inclusive of 9 subjects, more than 200 journals)

Providing 24-hour high-quality service

User-friendly online submission system

Fair and swift peer-review system

Efficient typesetting and proofreading procedure

Display of the result of downloads and visits, as well as the number of cited articles

Maximum dissemination of your research work

Submit your manuscript at: http://papersubmission.scirp.org/

Or contact ce@scirp.org 